\title{
Air Flow Thermal and Dynamic Behavior Inside Ventilated Cavities
}

\author{
Y. Harnane ${ }^{1,2 *}$, S. Bouzid ${ }^{1}$ and A. Brima ${ }^{2}$ \\ ${ }^{1}$ Department of Mechanical Engineering, Faculty of Sciences and Applied Sciences, \\ University of Larbi ben M'hidi, Oum El Bouaghi, Algeria \\ *E-mail: harnane_y@yahoo.fr \\ Phone: +213560000944; Fax: +21332691603 \\ ${ }^{2}$ Mechanical Engineering Laboratory (LGM), University of Mohamed Khider Biskra, \\ Algeria
}

\begin{abstract}
This work presents a numerical study of the dynamic and thermal behavior of the air flow circulating in the vertical rectangular cavity of height $\mathrm{H}$ and width $\mathrm{W}$. The geometry consists of a vertical wall of low thermal conductivity and an opposite wall which acts as a ventilated facade with five openings subjected to a heat flow. The methods of analyzing the flow input and output behavior through the openings throughout the ventilated facade, make the use of CFD tools "Fluent 14.0" mandatory for a detailed description. The flow is considered to be turbulent, steady, incompressible and bi-dimensional and computations are performed using the standard k- $\varepsilon$ and RNG k$\varepsilon$ models for Rayleigh number $\approx 10^{11}$. The results included mean velocity profiles; flow structure and thermal field which were presented and discussed. A comparative study with conventional cavity (closed) and classical cavity with two openings (input-output) under the same thermal conditions was conducted to quantify energy savings by the use of such configuration. The increase of the number of the openings enhances the wall cooling. Moreover, above a certain heat flux absorbed by the ventilated wall, natural cooling is obsolete, it is necessary to use forced devices.
\end{abstract}

Keywords: Natural convection; chimney effect; ventilated open facades; standard k- $\varepsilon$; RNG k- $\varepsilon$ turbulence models.

\section{INTRODUCTION}

The joint facade is a passive conditioning system. The solar radiation on the external walls heats them and activates the convection inside the air gap, which generates ventilation with an upward air stream that enters and exits the cavity through the openings. When this stream exits the cavity through the upper part openings, it extracts the thermal energy. In this way, wall temperature and heat flow toward the building interior is reduced, decreasing the energy needed for air conditioning. In these facades, the air temperature in the cavity is lower than the temperature reached in a conventional facade (closed). The thermal energy extracted via ventilation depends on the air mass flow circulating inside the cavity and its efficiency depends on the internal wall temperature. As this ventilation is produced by solar radiation, the ventilated facade by openings is particularly interesting for areas where peak demand for energy occurs during summer. In recent years, confined spaces have become a very popular building system due to their ability to decrease thermal cooling loads, to reduce moisture 
problems and their easy installation, not only in new buildings but also in rehabilitated buildings.

Study of fluid's thermal and dynamic behavior in ventilated facades with openings is difficult because of the complex air flows generated inside cavity which is naturally ventilated. Ventilated open facades can help to achieve significant energy savings in climates with hot summers and cold winters [1]. Ambient control generates strong energetic growth in the cooling sector. Ventilation is the action that creates an air renewal and its importance: no power consumption, silent operation, non-existent maintenance, economic achievement and zero cost of use.

In literature, many more or less recent works in which several experimental models and numerical simulations have been realized to evaluate the performances of these ventilated walls and their advantages compared to classical constructive choices [2-4]. From a thermal point of view, ventilated wall is interesting since it involves various heat modes, particularly the convective exchanges occurring in vertical heated channel where air circulates at low velocity under a hot surface producing a natural phenomenon called "chimney effect".

The main difference with conventional ventilated facades is that air can enter and exit the air cavity through the openings circulating along the cavity at an inhomogeneous rate. Despite this ventilation system is very widespread, scientific literature on this subject is insufficient to allow design and evaluation general rules. For this, our goal is to study the flow dynamic and thermal behavior inside the cavity (air gap). To simplify the analysis, solar radiation and wind effects are ignored. Experiment conditions indicate that flow inside the ventilated cavity is driven by natural thermal convection, which means that the external air comes in and out freely from the ventilated cavity at any point. Numerical simulation is confronted with calculation and memory space problems especially when it concerns three-dimensional dimensions and particularly in complex geometry, in presence of complex physical phenomena (such as turbulence, when the temperature differences are large).

However, it stills the least expensive and most used method because of calculator's capacities fast evolution which allowed noticeable progress to understand natural convection phenomenon, especially when it regards turbulent flows. Study of natural convection in confined and ventilated spaces has been subjected to numerous works, particularly in thermal insulation field and for embedded systems, for example, the studies of Saelens D and Hens H. [5], Sanjuan C et al. [6] etc. These studies are either numerical or experimental and natural convection - solar radiation coupling is taken into account in the majority of these studies.

This study considers a vertical cavity of $0.825 \mathrm{~m}$ height and $0.04 \mathrm{~m}$ width with openings of $5 \mathrm{~mm}$ height on the heated wall. The latter is composed by four panels of the same height set side-by-side allowing air entry and exit through the openings. To simplify analysis, radiation and wind effect are neglected. Numerical approach is used to handle the mixed turbulent convection with high Grashof number. The CFD code Fluent [7] is adopted to achieve computations where turbulence is modeled by both standard $\mathrm{k}-\varepsilon$ and RNG $\mathrm{k}-\varepsilon$ models.

\section{MATHEMATICAL FORMULATION}

Since the flow is turbulent, the fluctuating variables are introduced in Navier Stokes and energy equations; this gives new variables which need to be modeled (Reynolds stresses $-\rho \overline{u_{i} u_{j}}$ and turbulent heat flux $\rho \overline{u_{j}}$ h). The resulting steady-state RANS equations, 
assuming that air is Newtonian and incompressible and dropping the bar for averaged quantities, are:

Conservation of mass:

$\frac{\partial}{\partial x_{j}}\left(\rho U_{j}\right)=0$

Conservation of momentum:

$\frac{\partial}{\partial \mathrm{x}_{\mathrm{j}}}\left(\rho \mathrm{U}_{\mathrm{i}} \mathrm{U}_{\mathrm{j}}\right)=-\frac{\partial \mathrm{P}}{\partial \mathrm{x}_{\mathrm{i}}}+\frac{\partial}{\partial \mathrm{x}_{\mathrm{j}}}\left(\tau_{\mathrm{ij}}-\rho \overline{\mathrm{u}_{\mathrm{i}} \mathrm{u}_{\mathrm{j}}}\right)+\mathrm{S}_{\mathrm{M}, \text { buoy }}$

Conservation of energy:

$\frac{\partial}{\partial x_{j}}\left(\rho U_{j} h_{t o t}\right)=\frac{\partial}{\partial x_{j}}\left(\lambda \cdot \frac{\partial T}{\partial x_{j}}-\rho \overline{u_{j} h}\right)+\left[U_{i}\left[\tau_{i j}-\rho \overline{u_{i} u_{j}}\right]\right]$

Where $\tau$ is the molecular stress tensor and $S_{M, b u o y}$ is the term added from buoyancy effect $S_{\text {M,buoy }}=\left(\rho-\rho_{\text {ref }}\right)$ g. The mean total enthalpy is given by: $h_{\text {tot }}=h+1 / 2\left(U_{i} U_{i}\right)+k$. The turbulent kinetic energy contribution in total enthalpy is given by, $\mathrm{k}=1 / 2\left(\overline{\mathrm{u}_{\mathrm{i}}^{2}}\right)$

\section{Turbulence Models}

Computations were performed using standard k- $\varepsilon$ [8] and RNG k- $\varepsilon$ [9] turbulence models. These two-equation models based on eddy viscosity concept are widely used as they offer a good compromise between numerical effort and computational accuracy. Numerically, the standard k- $\varepsilon$ model is robust and consistent [10] and treats physics in simplified manner. Chen [11] previously evaluated the performance of five k- $\varepsilon$ models for the simulation of forced convection, natural convection and mixed convection room airflow. The results from the RNG k- $\varepsilon$ model were slightly better than those from the standard k- $\varepsilon$ model and the other models were not stable. Chen recommended the RNG $\mathrm{k}-\varepsilon$ model for indoor airflow simulation. The simplified approach represented by the turbulent viscosity hypothesis is that of the hypothesis formulated a century ago by Boussinesq, which consists to express algebraically the Reynolds stress tensor as a function of the average deformation ratio:

$-\rho \overline{\mathrm{u}_{\mathrm{i}} \mathrm{u}_{\mathrm{j}}}=\mu_{\mathrm{t}}\left(\frac{\partial \mathrm{U}_{\mathrm{i}}}{\partial \mathrm{x}_{\mathrm{j}}}+\frac{\partial \mathrm{U}_{\mathrm{j}}}{\partial \mathrm{x}_{\mathrm{i}}}\right)-\frac{2}{3} \delta_{\mathrm{ij}}\left(\rho \mathrm{k}+\mu_{\mathrm{t}} \frac{\partial \mathrm{U}_{\mathrm{k}}}{\partial \mathrm{x}_{\mathrm{k}}}\right)$

where $\mu_{t}$ is the turbulent viscosity that connects the turbulence kinetic energy with its dissipation via the relation: $\mu_{\mathrm{t}}=\rho \mathrm{C}_{\mu} \mathrm{k}^{2} / \varepsilon$.

\section{Standard $k-\varepsilon$ model}

This model is based on dynamic turbulent viscosity concept, where the viscosity $\mu_{t}$ is expressed as a function of the turbulent kinetic energy $\mathrm{k}$ and its dissipation ratio $\varepsilon$ : $\mu_{\mathrm{t}}=\rho \mathrm{C}_{\mu} \mathrm{k}^{2} / \varepsilon$. $\mathrm{k}$ and $\varepsilon$ quantities are obtained by solving their respective transport 
equations which complete the equations systems [12]. In this model, $\mathrm{C}_{\mu}$ is a constant equal to 0.09 .

\section{$R N G k-\varepsilon$ model}

The k- $\varepsilon$ RNG model, developed by Yakhot V. and Orszag S.A [9], is based on the socalled "renormalization" theory of the Navier-Stokes equations. Transport equations for turbulent generation and dissipation ratio are the same as those for the standard k- $\varepsilon$ model, but the constants for this model are found analytically using RNG theory. $\mathrm{C}_{\mu}=0.0845, \mathrm{C}_{\varepsilon 1}=1.42, \mathrm{C}_{\varepsilon 2}=1.68, \sigma_{\mathrm{T}}=0.9, \sigma_{\mathrm{k}}=1.0$ and $\sigma_{\varepsilon}=1.3$.

\section{Computational Domain}

The air circulates in a vertical rectangular cavity. The cavity with a height of $0.825 \mathrm{~m}$ and a width of $0.04 \mathrm{~m}$. The cavity consists of a left wall of low thermal conductivity and a straight wall that plays the role of a ventilated facade with five openings of $5 \mathrm{~mm}$. Air at outside temperature enters the cavity through the ventilated facade bottom openings, circulates in the air gap and exits through the top of the same facade (Figure 1). In the cavity, the ventilated right wall is in contact with the external environment.

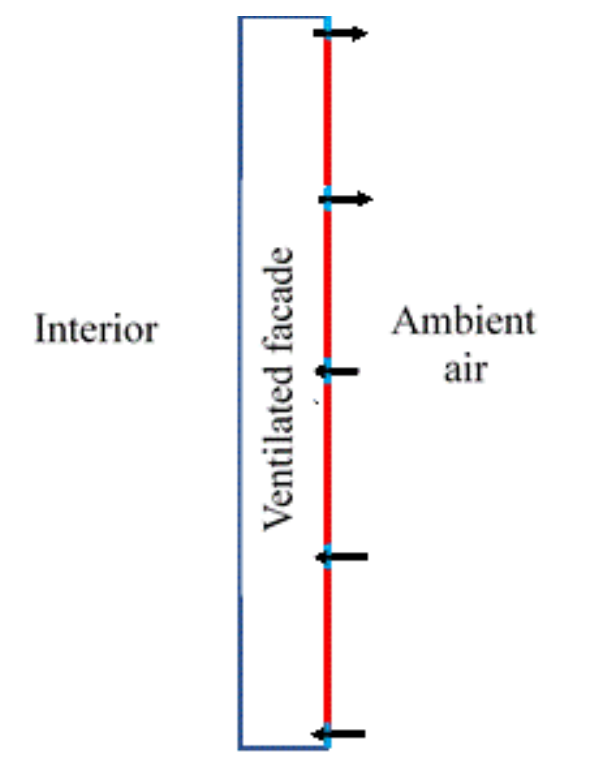

Figure 1. Geometric configuration.

\section{Boundary Conditions and Computational Procedures}

The panels constituting this wall are subjected to a surface heat flow of $300 \mathrm{~W} / \mathrm{m}^{2}$. The left wall is subjected to a convective transfer with coefficient $h=8 \mathrm{~W} / \mathrm{m}^{2} \mathrm{~K}$ corresponding to the internal flow conditions [13]. The high and low walls are maintained adiabatic. In our study, the geometry is naturally ventilated and the air velocity at the entrance of the openings is unknown, the entry and exit conditions for this type of model are of "pressure-inlet" and "pressure-outlet" type, respectively. These conditions result from Bernoulli's theorem (Local) [14]: At the inlet section $\mathrm{P}(\mathrm{x}=1$, $\left.\mathrm{y}_{\text {inlet }}\right)=-\frac{1}{2} \mathrm{u}\left(\mathrm{x}=1, \mathrm{y}_{\text {inlet }}\right)^{2}$ and at the outlet section: $\mathrm{P}\left(\mathrm{x}=1, \mathrm{y}_{\text {outlet }}\right)=0$ 
The studied flow regime is turbulent, a model selection is very important. In this type of ventilated cavity, the k- $\varepsilon$ RNG model is widely used and provides better results than other models k- $\varepsilon$ [15-17]. In contrast, for the closed cavity, the simple model k- $\varepsilon$ was chosen. In all cases enhanced wall treatement is choosen. The Enhanced Wall Treatment option provides better solutions on highly refined wall meshes, it is recommended for general single-phase fluid flow problems when using the k- $\varepsilon$ model [7]. The numerical resolution method in the ventilated cavity is as follows [14]: the resolution of the discretized equations is carried-out by the "SIMPLE" algorithm; "PRESTO" scheme for pressure and "QUICK" scheme for convective terms. For the closed cavity, the procedure is as follows: the resolution of the discretized equations is carried-out by the algorithm "COUPLED"; "2 ${ }^{\text {nd }}$ Order" scheme for diffusive terms and "Upwind" scheme for convective terms.

\section{RESULTS AND DISCUSSION}

The methods to analyze the flow input and output behavior via the openings throughout the vented facade make the use of CFD tools mandatory for a detailed description. The main objective of this work is to study the dynamic and thermal phenomena that take place in a ventilated facade cavity under the effect of a thermal flow and compare this behavior with that of a conventional cavity (closed) and conventional one with twoopenings (input-output) under the same thermal conditions to quantify energy savings by the use of such configuration.

\section{Grid Independency Solution}

To check the mesh convergence and its effect on our results, some tests were carried-out by varying the size, number and distribution of the meshes inside the cavity. We performed a series of calculations for each study case with three refined structured meshes near the walls. The mesh tests prove that the cavity center does not require a mesh as fine as the regions close to the wall. Note that the velocity profiles are similar and the difference in the results between the selected meshes is very low, not exceeding $1 \%$ at different ratings, as shown in Figures 2(a), 2(b) and 2(c). To perform the final calculations, a mesh with a maximum number of cells was used.

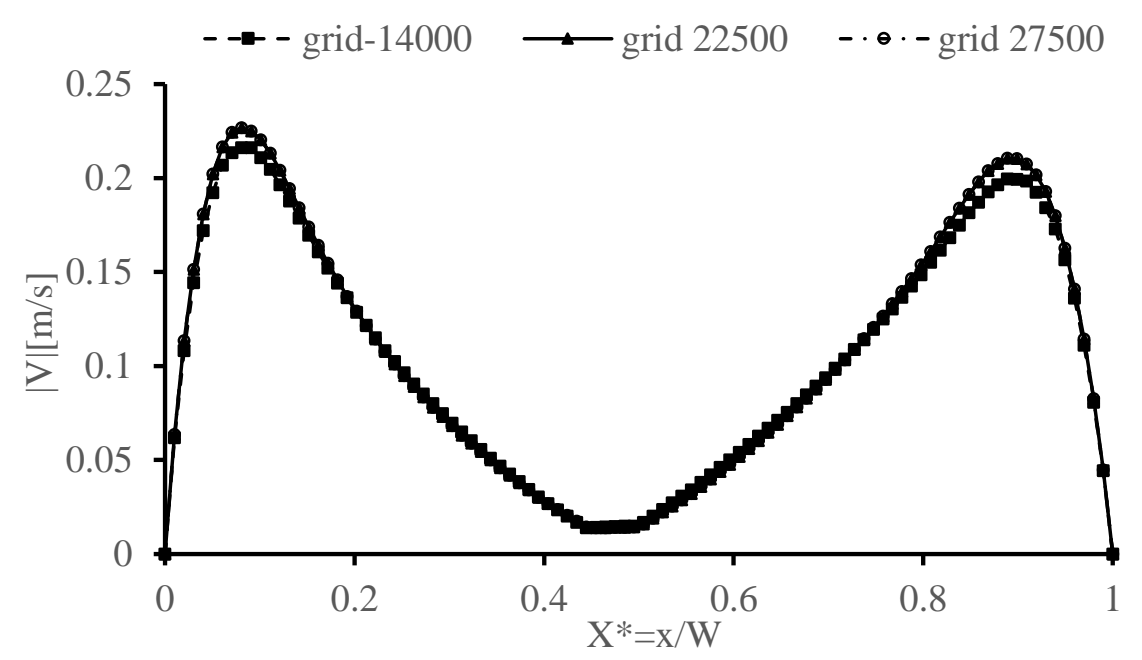

(a) 


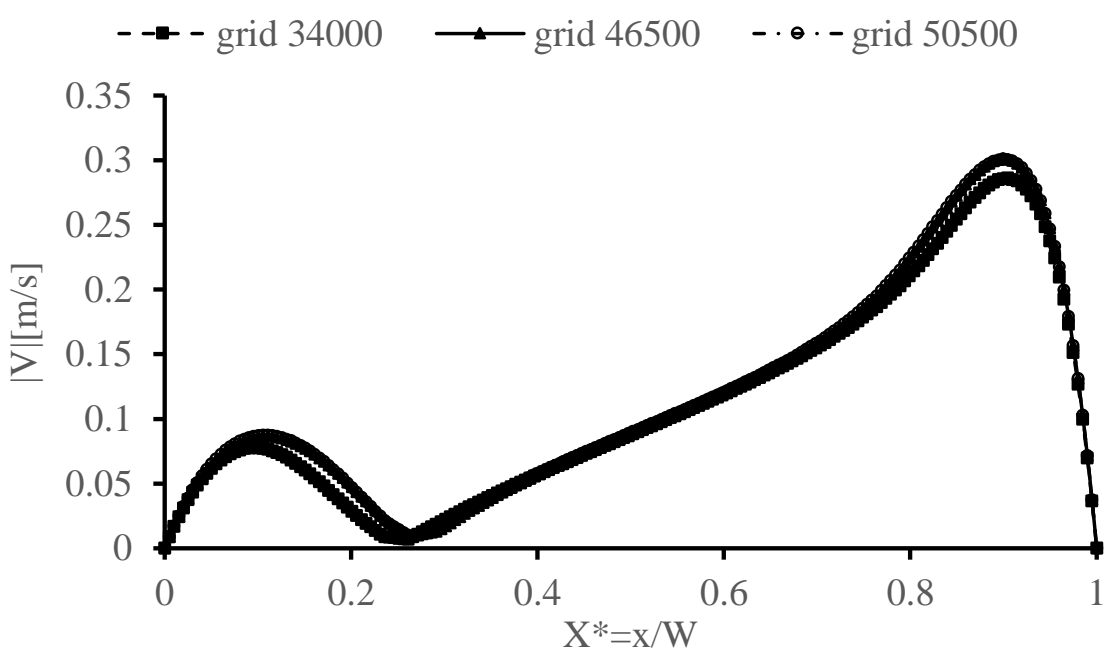

(b)

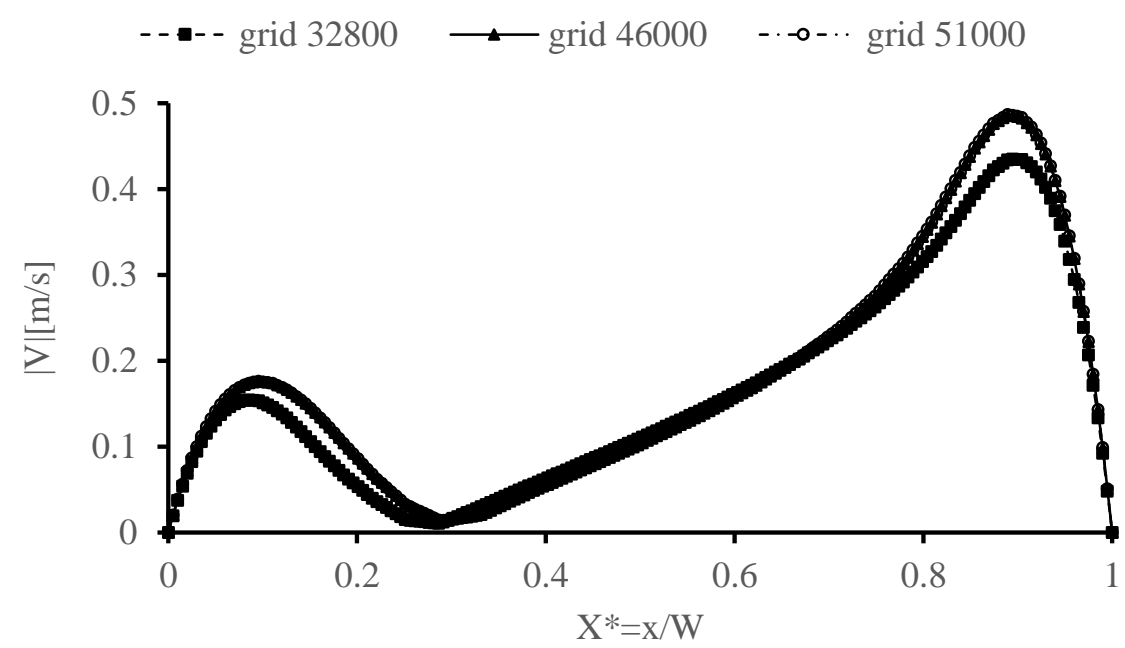

(c)

Figure 2. Effect of grid size for (a) conventionnel cavity; (b) ventilated cavity with several openings and; (c) ventilated cavity with two openings at $\mathrm{y} / \mathrm{H}=0.848$.

\section{Flow Field}

The average flow is lined-up with the cavity walls due to buoyancy forces. The upward ventilation flow is marked by discontinuities at the openings. In the cavity, the air enters through the openings located in the lower part and leaves the domain through the openings located in the upper part. Recirculation areas are formed near the panels at the fresh air inlet. In general, the air inside the cavity forms an upward flow with local discontinuities at the openings, which makes the flow complicated, inhomogeneous and asymmetrical as shown in Figure 3. 


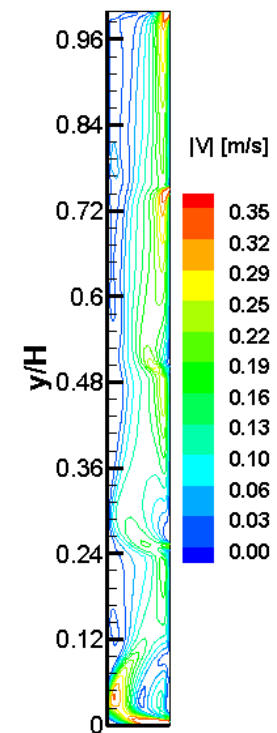

(a)

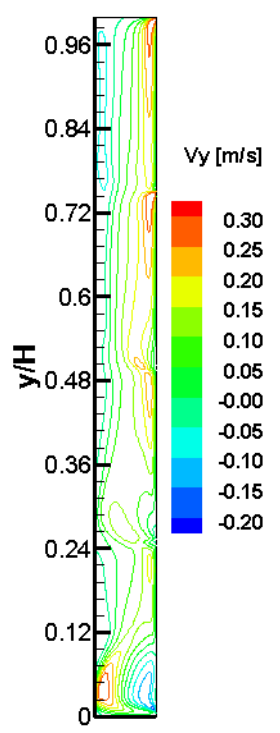

(b)

Figure 3. Dynamic field of (a) velocity magnitude and; (b) vertical velocity.

The heat flow increases the panel's temperature and, consequently, the air temperature in the confined space. Thus, the buoyancy forces generate an upward flow in the cavity. Figure 4 shows the average total velocity and the vertical velocity component of the flow at the median vertical plane, along the cavity. The relationship between them indicates that the velocity vertical component is the main component responsible for movement in the ventilated cavity. The velocity profiles for different dimensions $(y / H)$ show an upward flow that does not maintain a homogeneous profile along the cavity due to the openings presence. In the first panel lower part, the velocity profile shows that the flow enters with a jet separated from the hot wall as shown in Figure 5. Figure 6 compares the vertical velocity profiles in the ventilated cavity and the conventional one. The air flow in the ventilated cavity grows across the entire width and does not form a convective loop as in the sealed cavity facade.

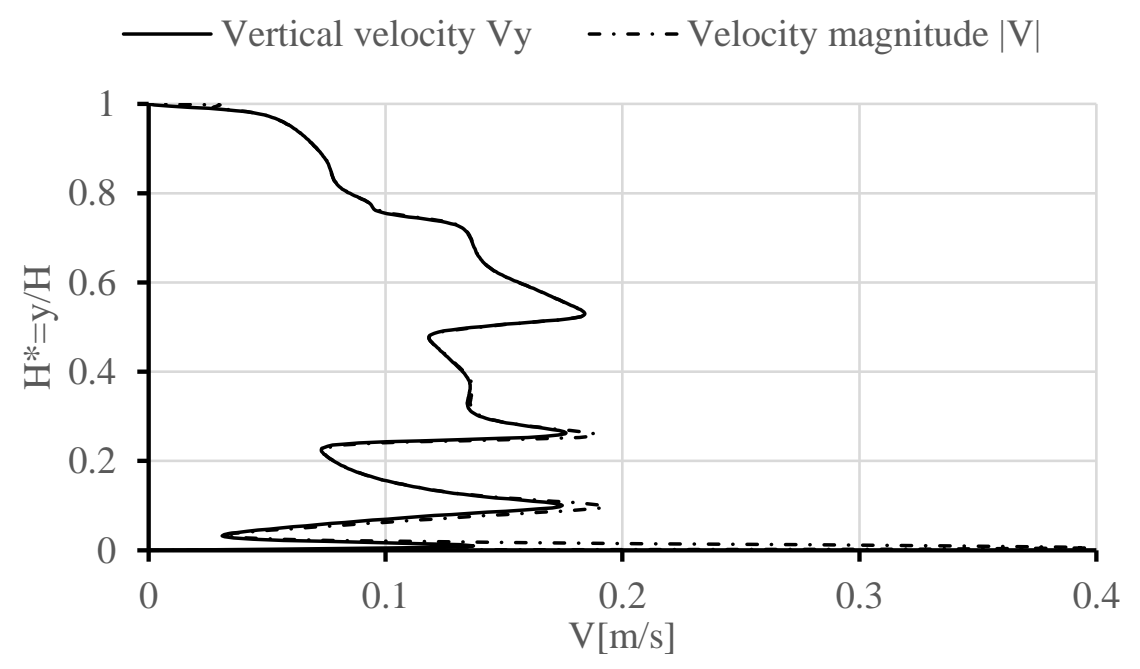

Figure 4. Evolution of $|\mathrm{V}|$ and $\mathrm{Vy}$ along the height $(\mathrm{x} / \mathrm{W}=0.5)$. 


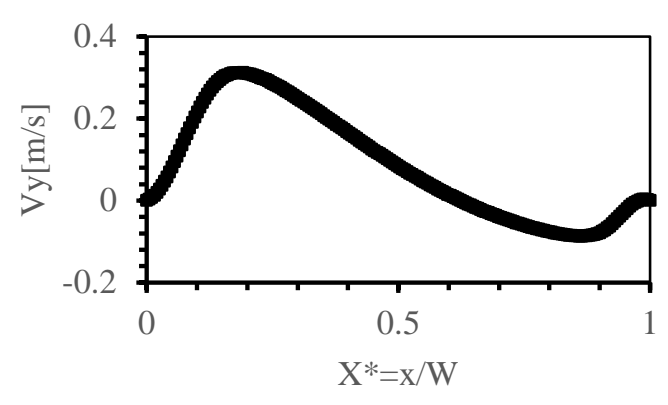

(a)

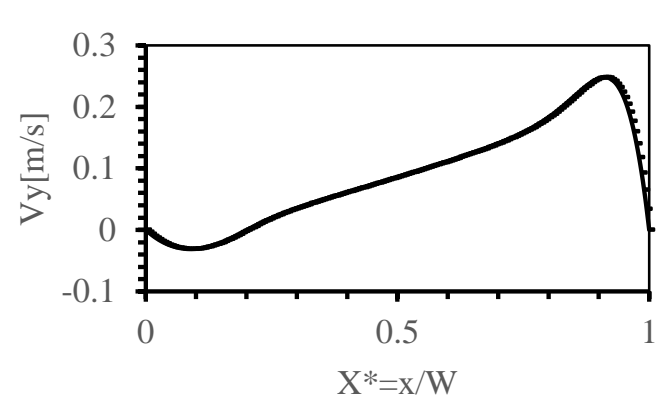

(c)

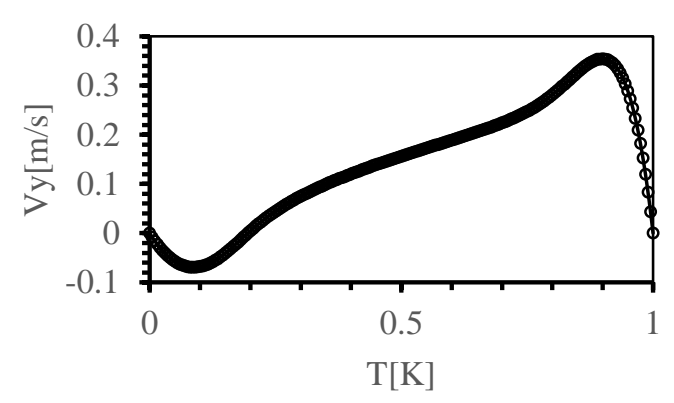

(e)

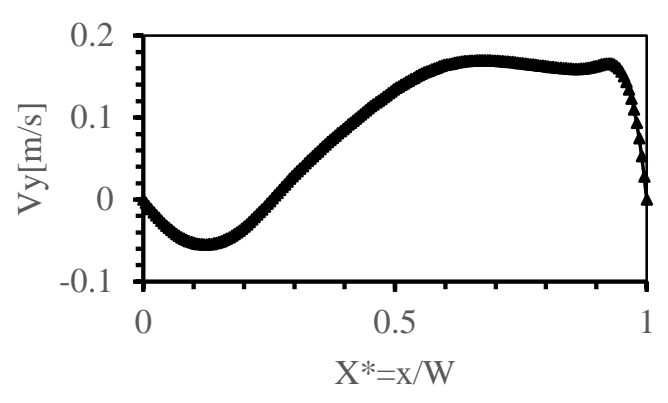

(b)

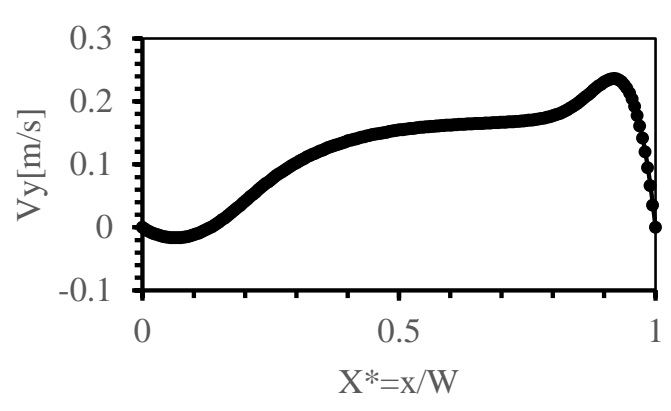

(d)

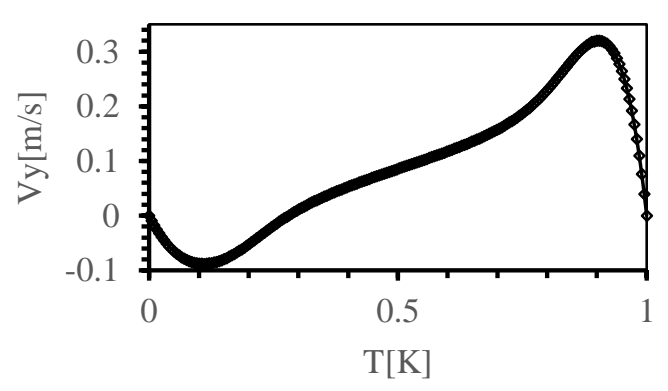

(f)

Figure 5. Mean vertical velocity, $\mathrm{Vy}$ as a function of height, $\mathrm{X}^{\prime}=\mathrm{x} / \mathrm{W}$.

In addition, the profiles indicate much higher velocity values in the case of the ventilated cavity. These two characteristics promote the cavity left wall cooling, which is one of the advantages of this kind of cavity. Figure 7 shows a general scheme of the flow behavior. The flow enters through the lower openings but not with the same rate. The total flow that enters the cavity is distributed through the openings located below the mid-height $(\mathrm{y} / \mathrm{H}=0.5)$. Note that the mass flow percentage decreases with the openings height. On the upper part of the enclosure, the trend is inversed, the output mass flow distribution increases with height. The pressure development with height and at mid-width of the cavity $(\mathrm{x} / \mathrm{W}=0.5)$ is shown in Figure 8 . The pressure profile indicates a depression in the cavity lower part which forces the air entry through the openings. The pressure balance is reached in the region near the mid-height cavity. The overpressure forces the flow to exit through the upper openings and the pressure differences inside the ventilated cavity increase with height. 


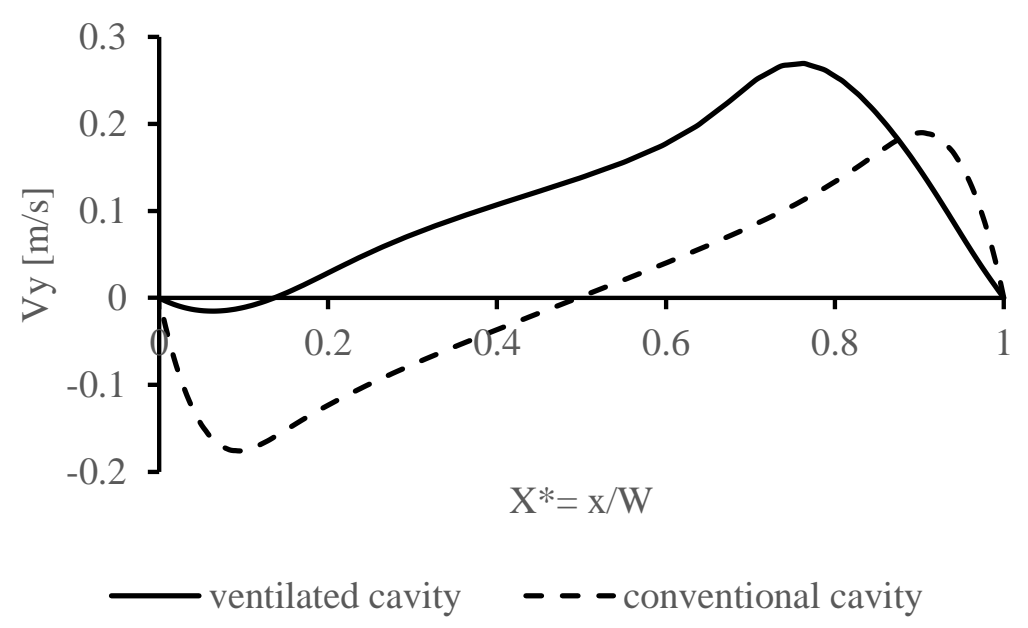

Figure 6. Profiles of vertical velocities at the mid-height of the cavity $(\mathrm{y} / \mathrm{H}=0,5$; ventilated cavity and closed cavity).

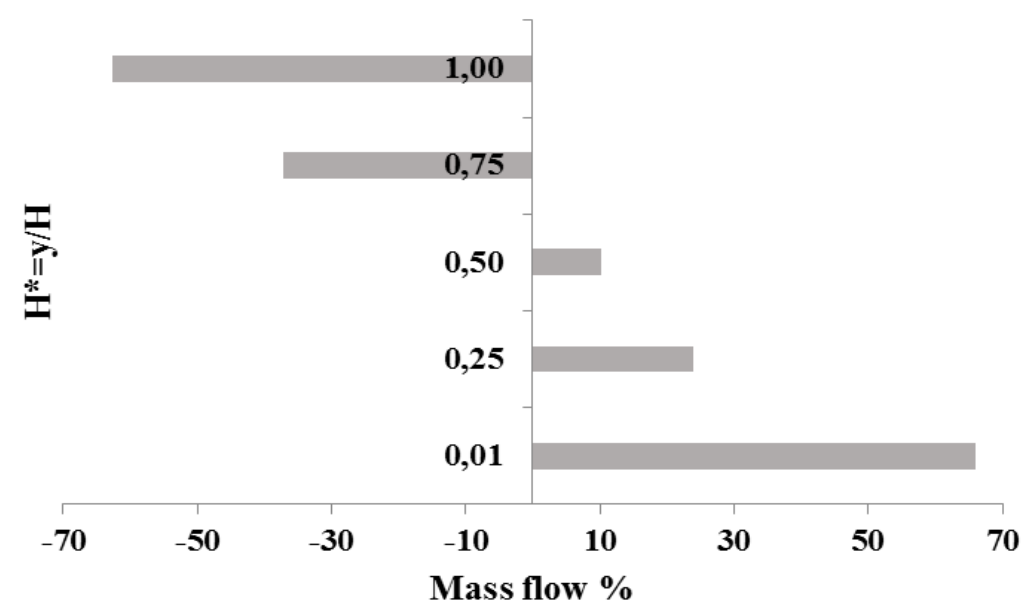

Figure 7. Mass flow through openings (positive: incoming; negative: outgoing).

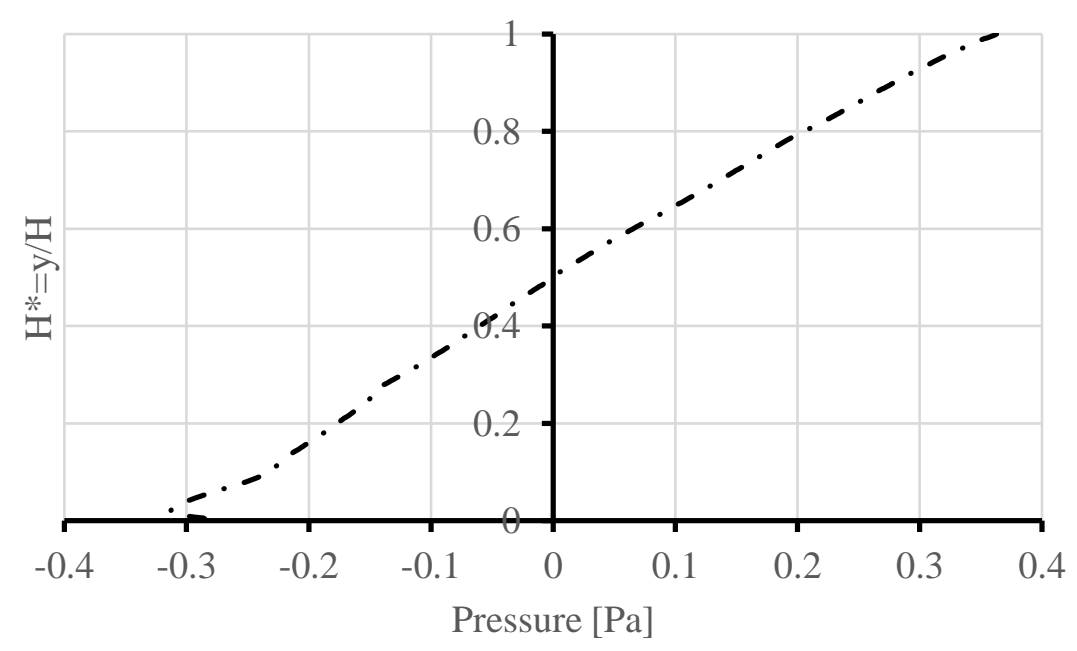

Figure 8. Pressure profile in the ventilated cavity ( $\mathrm{x} / \mathrm{W}=0.5$ et flux=300 W/m²). 


\section{Thermal Field}

One of the most claimed benefits for using ventilated facades is their ability to reduce cooling thermal loads. The improved thermal performance of these facades relies on the buoyancy: the external coating panels are heated and generate an upward air mass flow (via natural convection) which enters and exists from the cavity through the openings. This flow eliminates some portion of the heat loads, reducing the heat transfer to the internal environment. This phenomenon can also be noticed in other ventilated facade typologies, with openings only located at façade bottom and top, due to an entry at low flow and high temperatures reached on the air gap high part [1] as shown in Figure 9.

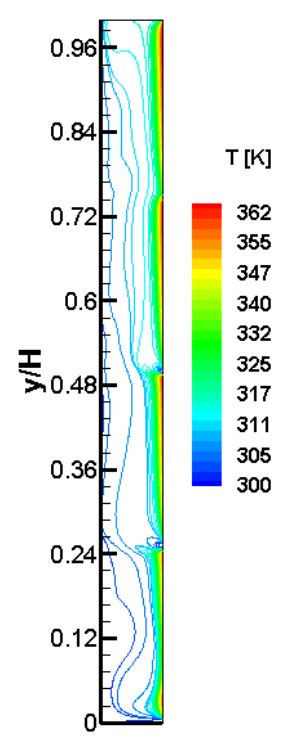

Figure 9: Thermal field.

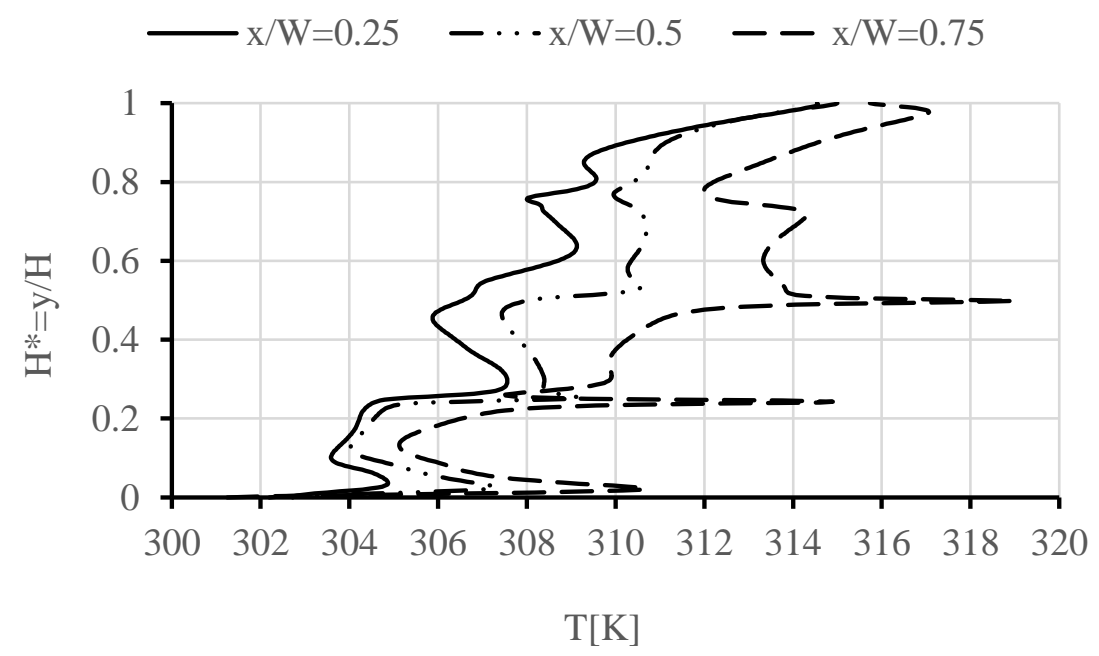

Figure 10. Evolution of the vertical temperature in the cavity. 


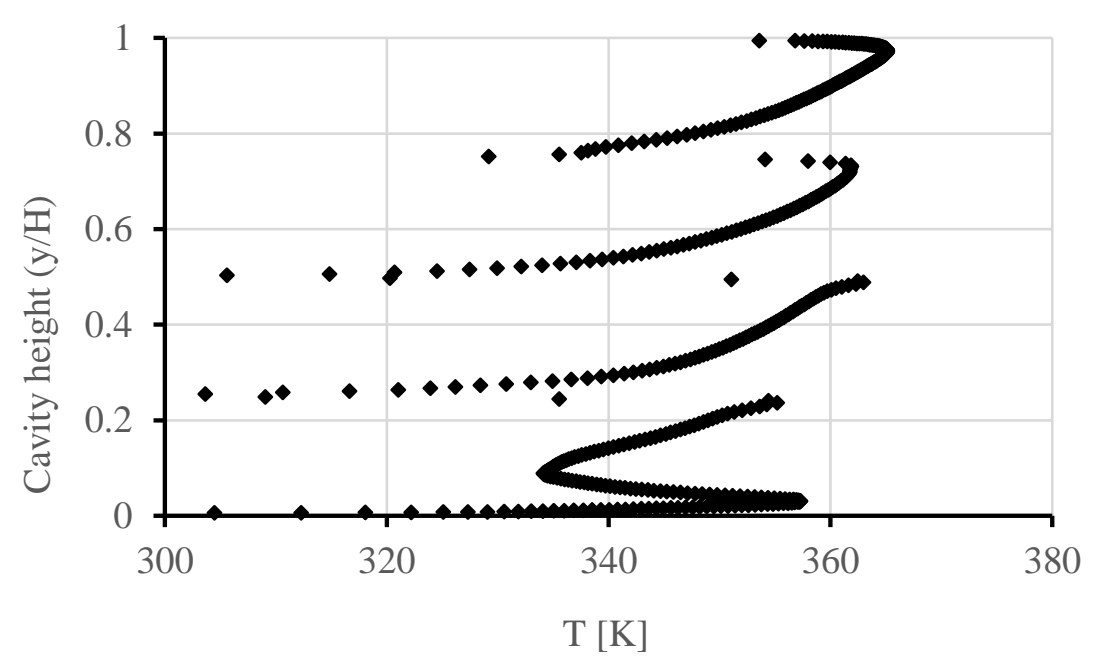

Figure 11. Vertical evolution of the heated panel's temperature (at $300 \mathrm{~W} / \mathrm{m}^{2}$ ).

The vertical temperature evolution inside the cavity with ventilated facades is shown in Figure 10. The curves correspond to different width positions, near the panels $(\mathrm{x} / \mathrm{W}=0.75)$, at cavity middle $(\mathrm{x} / \mathrm{W}=0.5)$ and near the right wall $(\mathrm{x} / \mathrm{W}=0.25)$. In the cavity with ventilated facades, the external air enters the cavity through the openings at the bottom part. This air is fresher than the wall heated by the flow; it generates a ventilation effect, which cools down. Panels are cooled inside the areas near the openings of the fresh air entry as shown in Figure 11. Panels mean temperature increases with height, and it is not homogeneous as shown Table 1.

Table 1. Panels mean temperature

\begin{tabular}{ccccc}
\hline Panels & $\begin{array}{c}\text { Panel 1 } \\
(\text { Bottom) }\end{array}$ & Panel 2 & Panel 3 & $\begin{array}{c}\text { Panel 4 } \\
\text { (Top) }\end{array}$ \\
\hline Mean temperature [K] & 343.53 & 349.13 & 351.21 & 355.33 \\
\hline
\end{tabular}

\section{Comparison of Energetic Performances of Studied Cavities}

To conclude the effectiveness of such configuration compared to a conventional one, a comparison of temperatures inside ventilated cavities with two and several openings was conducted. The main purpose of a facade with several openings is to cool the air space inside the cavity that cools the left wall which represents the room outer facade (bedroom, office, etc.). The air temperature in the cavity is lower in the ventilated cavity with several openings compared to the conventional one and consequently the transferred heat inside the room is lower.

Figures 12 and 13 show temperatures at mid-width cavity and left wall, respectively. The left wall is cooled by the flows entering the cavity. Air inside the conventional cavity (with two openings) is hotter than air inside the ventilated cavity with multiple openings for the same conditions. 


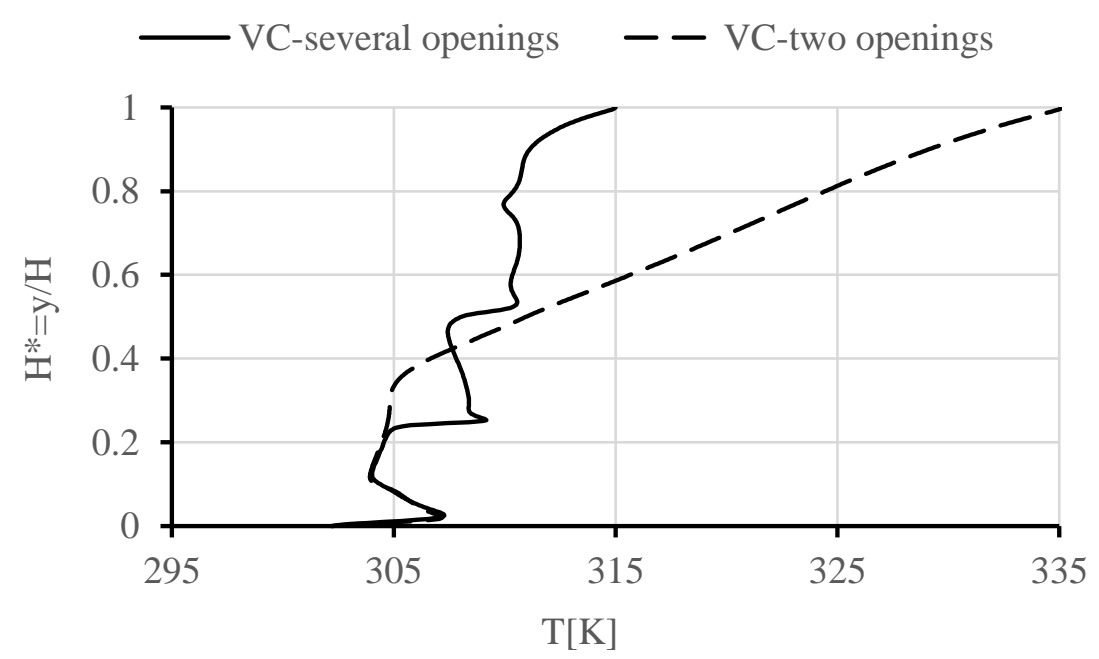

Figure 12. Vertical evolution of vertical temperature at the mid-width of the two cavities studied $\left(\mathrm{x} / \mathrm{W}=0.5\right.$ for the same flux $\left.=300 \mathrm{~W} / \mathrm{m}^{2}\right)$.

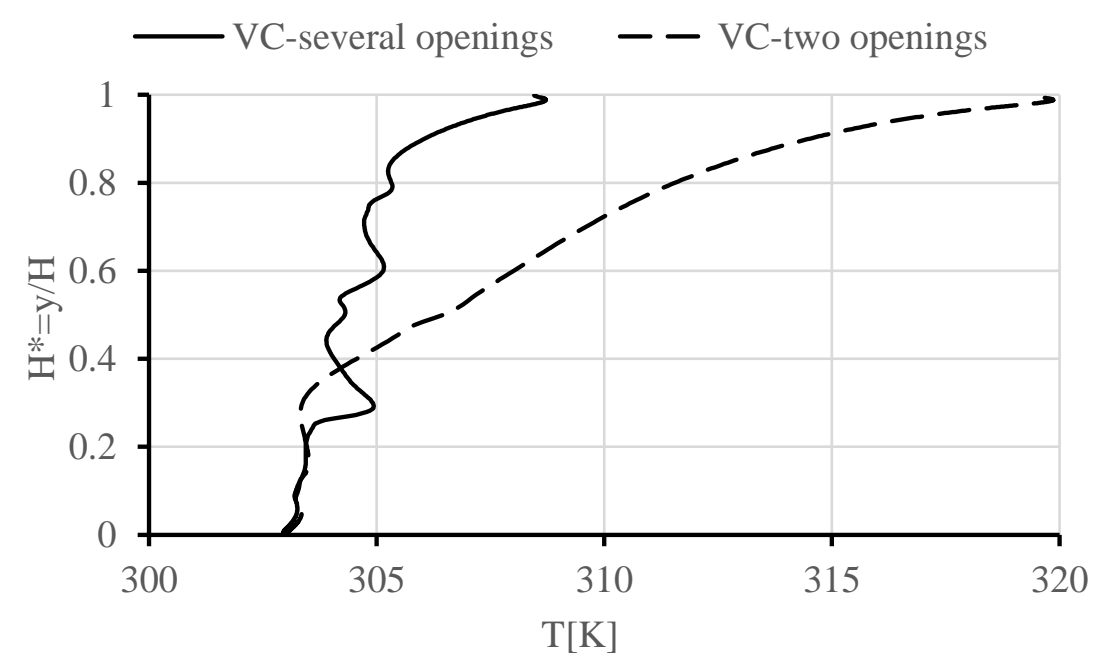

Figure 13. Vertical evolution of the left wall's temperature of the two cavities $(\mathrm{x} / \mathrm{W}=$ 0.5 for the same flux $=300 \mathrm{~W} / \mathrm{m}^{2}$ ).

The heat flow absorbed by the right wall panels is dissipated inside the cavity. Although the heat flux transmitted in the multi-openings ventilated cavity is larger than that transmitted in the conventional cavity, these flows are mainly recovered by the upward ventilation flows and transported outward through the cavity top outlet openings (Figure 14). The ventilation mass flow in the cavity, as a function of heat flow (absorbed), is shown in Figure 15. Note that the chimney effect increases with heat flow, so for each flow value, the mass flow increases.

In Figure 16, note that from the heat flow of $400 \mathrm{~W} / \mathrm{m}^{2}$, the entering air mass flow has no significant effect on the left wall temperature. The two temperatures corresponding to both heat flow values of $400 \mathrm{~W} / \mathrm{m}^{2}$ and $525 \mathrm{~W} / \mathrm{m}^{2}$ are very close. We can conclude that the natural cooling in this case is insufficient; a mechanical depression has become necessary to move to mixed convection. 


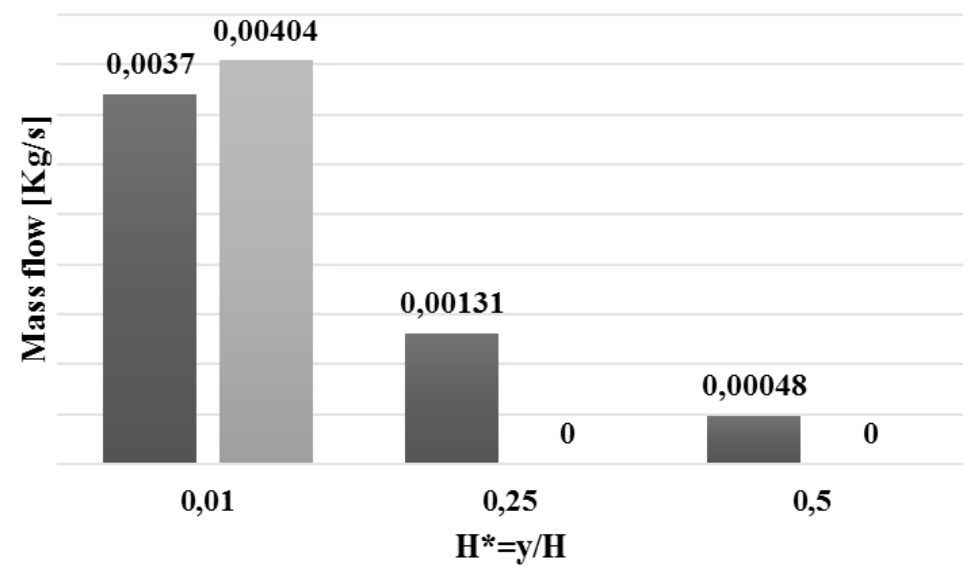

Figure 14. Comparison of the mass flow rates in the two cavities at flux $=300 \mathrm{~W} / \mathrm{m}^{2}$.

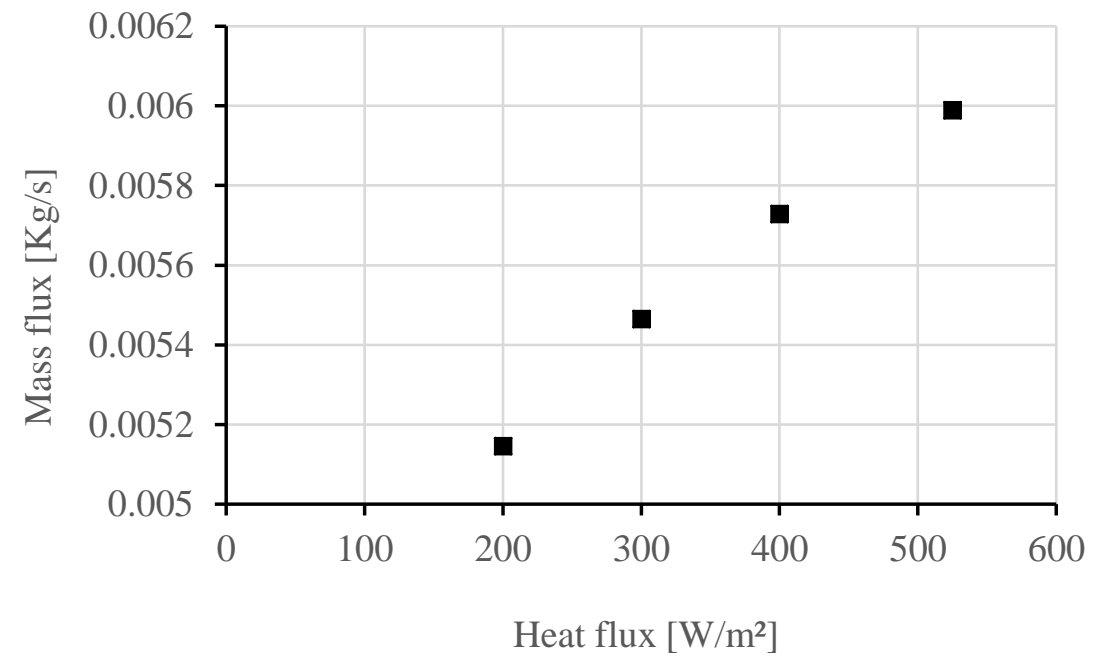

Figure 15. Mass flow rate as a function of the heat flow absorbed by the wall of the ventilated facade for cavity with several openings.

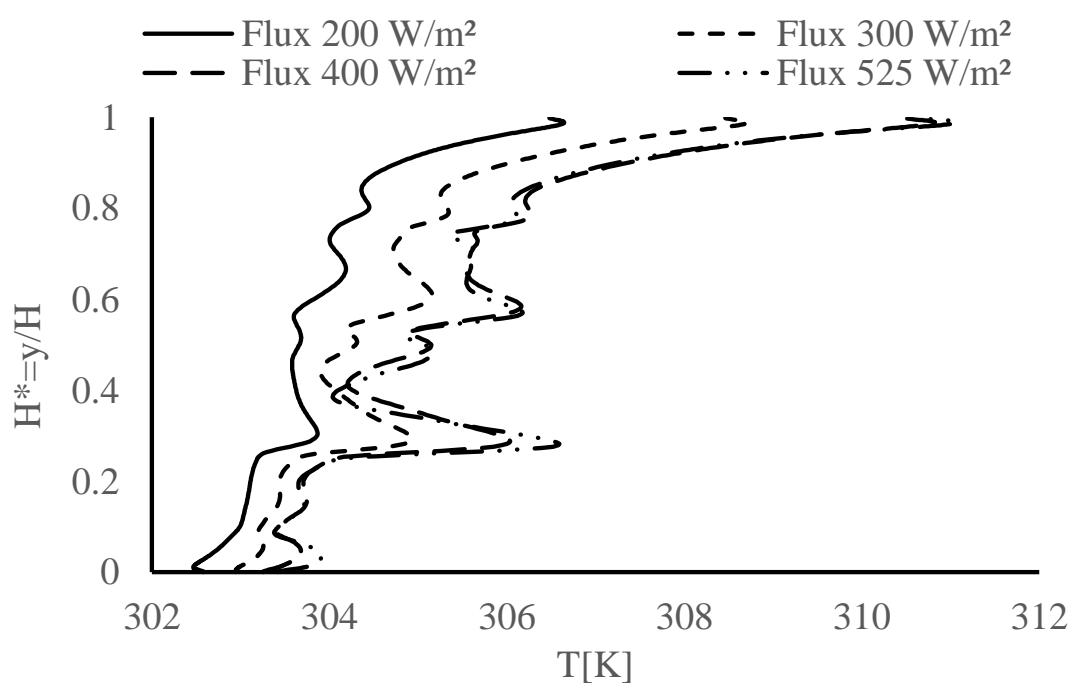

Figure 16. Vertical evolution of the left wall temperature for different flux values. 


\section{CONCLUSION}

The turbulent flow inside the ventilated cavity was accurately simulated via the CFD Fluent calculation code. In order to study the flow dynamic and thermal structure in the air gap, the energetic performances of the cavity left wall have been evaluated. The main conclusions are as follows:

i. The increase of openings number inside the ventilated wall increases the entering air mass flow and consequently the air gap cooling, which decreases the left wall temperature.

ii. The increase in the heat flow that is absorbed by the ventilated wall increases the mass flow in the cavity. At a certain value of the heat flow, it is recommended to impose a velocity condition at the inlet to increase the cavity energy performance.

\section{REFERENCES}

[1] Sanjuan C, Suárez MJ, Blanco E, Heras MR. Development and experimental validation of a simulation model for open joint ventilated facades. Energy \& Buildings 2011; 43(12): 3446-56

[2] Oesterle R, Lieb R, Lutz M, Heusler W. Double Skin Facades - Integrated Planning, Prestel verlag. Germany, 2001.

[3] Brun A, Amélioration du confort d'été grâce à la ventilation de l'enveloppe, Thèse de doctorat, Université de Grenoble, France, 2011.

[4] Imessad K, Messaoudene NA, Belhamel M. Performances of the BarraCostantini passive heating system under Algerian climate conditions, Renew. Energy, 2004; 29(3); 357-367.

[5] Saelens D, Hens H. Evaluating the Thermal Performance of Active Envelopes. In: Proceedings of Performance of Exterior Envelopes of Whole Buildings VIII: Integration of Building Envelopes. Clearwater Beach, Florida: 2001; 243-7.

[6] Sanjuan C et al. Experimental PIV techniques applied to the analysis of natural convection in open joint ventilated facades. Energy Procedia, 2011; 30; 12161225.

[7] FLUENT User's Guide, Fluent Inc., Release 14.0, November 2011.

[8] Launder BE, Spalding DB, Lectures in Mathematical Models of Turbulence, Academic Press, London, 1972.

[9] Yakhot V and Orszag SA., Renormalization group analysis of turbulence. I, Basic theory, Journal of Scientific Computing, 1986; 1(1); 3-51.

[10] Pulat E, Ersan HA, Numerical simulation of turbulent airflow in a ventilated room: Inlet turbulence parameters and solution multiplicity. Energy and building, 2015; 93; 227-235.

[11] Chen Q, Comparison of different k- _ models for indoor airflow computation, Numer. Heat Transf. B: Fundam, 1995; 28; 353-369.

[12] Bredberg J, On two-equation eddy-viscosity models. Department of thermos fluid dynamics. Chalmers university of technology, Göteborg, Sweden, 2001.

[13] ASHRAE Handbook Fundamentals (S.I.), American Society of Heating, Refrigerating and Air Conditioning Engineers Inc., 2013.

[14] Desrayaud G et al., Benchmark solutions for natural convection flows in vertical channels submitted to different open boundary conditions, International Journal of Thermal Sciences, 2013; 72, 18-33. 
[15] Wang X, Prédiction et analyse numérique d'écoulements turbulents avec transfert thermique dans des cavités ventilées à l'aide d'un modèle à relaxation elliptique. Thèse de Doctorat. Université de Lille 1. 2009.

[16] Shih TH, Liou WW, Shabbir A., Yang Z, Zhu J. 1995, New k- $\varepsilon$ eddy viscosity model for high Reynolds number turbulent flows, Computers and Fluids, 1995; 24(3), 227-238.

[17] Yang Z, Shih TH. New Time Scale Based k - $\varepsilon$ Model for Near-Wall Turbulence, American Institute of Aeronautics and Astronautics Journal, 1993; 31; 11911198. 